\title{
EFFECT OF CURRENT PULSES ON ACTIVATION OF WELDED SURFACES OF PLATES FROM DISSIMILAR METALS (STEEL 20 + COPPER M1)
}

\author{
L.I. MARKASHOVA ${ }^{1}$, N.A. ONATSKAYA ${ }^{2}$ and L.Yu. DEMIDENKO ${ }^{2}$ \\ ${ }^{1}$ E.O. Paton Electric Welding Institute, NASU \\ 11 Kazimir Malevich Str., 03680, Kiev, Ukraine. E-mail: office@paton.kiev.ua \\ ${ }^{2}$ Institute of Pulse Processes and Technologies, NASU \\ 43-A Oktyabrsky Ave., 54018, Nikolaev, Ukraine. E-mail: iipt@iipt.com.ua
}

\begin{abstract}
Presented are the results of engineering process of welding of plates from dissimilar metals (steel $20+$ copper M1) under conditions of passing of high-density current pulses. Pulse current generator GIT-50, developed in the Institute of Pulse Processes and Technologies of the NAS of Ukraine, was used for welding processes activation. Application of complex investigation method allowed determining that different stages of the process of welded joint formation take place on a contact interaction surface of macroscopic size. It is caused by inhomogeneity of the real surfaces of solid bodies even at high class of their treatment. The results of examination of steel surface fine structure indicate that treatment of the preliminary compressed plates with the high-density pulses results in significant activation of the dislocation transformations, having significant effect on development of the third stage of solid state welding process, i.e. stage of volumetric interaction. 7 Ref., 2 Figures.
\end{abstract}

Keywords: welded joints, dissimilar materials, high-density current pulses, contact zone, electron microscopy, dislocation structure, activation of contact surface

Bimetallic joints, i.e. joints consisting of dissimilar on their properties metals and alloys [1, 2], are widely used in recent time in different products of current engineering. This allows using in full scope the specific properties of each of them as well as reducing the consumption of expansive and scarce metals and obtaining the parts with high service properties. Since the majority of combinations of dissimilar metals and alloys are characterized by different physical-chemical properties, it is clear that such type of differences will result in significant difficulties in receiving their quality welded joints, in particular, under fusion welding conditions. Therefore, different methods of pressure welding are used for performance of such types of dissimilar joints.

The necessary condition of welded joint formation for any method of pressure welding is a plastic deformation of the materials being welded [3, 4]. However, in some cases the processes of plastic deformation appear to be frozen due to high resistance of corresponding material to deformation. Then the special methods are used intensifying further deformation development. One of the methods, which has found application in industry, is a high-density pulse current $\left(\sim 10^{9} \mathrm{~A} / \mathrm{m}\right)$ impact of the deformed metal [5]. Earlier we have proved an activating effect of current pulses on plastic deformation of the preliminary compressed plates of similar materials (such as steel 20 + steel 20) under effect of high-density current pulses in pressure welding [6].
However, now scientific-and-technical literature contains no information on processes, taking place in the near-contact zones of metal of joined plates from dissimilar materials under such effect.

An aim of this work is to study an effect of high-density current pulses on the processes promoting activation of the contact surfaces of steel $20+$ copper M1 dissimilar metals in their joining in solid state.

Materials and procedures used for investigations. Plates of $170 \times 12 \times 2.5 \mathrm{~mm}$ size were taken as reference specimens, where a welding zone $l \approx 22 \mathrm{~m}$ was taken in the middle of the specimen.

Contact surface of the copper plate were polished to comb (roughness peaks) height from $\sim 8$ to $\sim 10 \mu \mathrm{m}$. Combs' height of the surface of more rigid steel plate after polishing made from $\sim 2$ to $\sim 3 \mu \mathrm{m}$. A difference on height of geometry of welded surfaces is caused by the fact that formation of physical contact in welding of dissimilar materials takes place, as a rule, as a result of microplastic deformation of softer material [4]. After cleaning the surfaces of both plates (acetone degreasing) the plastic deformation of microprojections of contact surfaces was carried out in special device at $50 \mathrm{MPa}$ pressure, and then pulse current of up to $10^{9}-10^{10} \mathrm{~A} / \mathrm{m}^{2}$ density was passed at pulse duration $\tau \geq 2 \cdot 10^{-4} \mathrm{~s}$ [7].

Investigation of processes of activation of joined surfaced in welding of the compressed plates from dissimilar metals using high-density current pulses were 
carried out using a complex of methods for analysis of physical processes, taking place in a contact zone of surfaces being welded. A method of scanning microdiffraction electron microscopy with JEOL JEM-200 CX unit (Japan) was used for examination of the peculiarities of dislocation structure change in sub-surface layers of metal in the contact zone. At that, the specimens for examination were prepared using the methods of special thinning by ionized beams of argon. It allows obtaining a real picture of distribution nature of dislocation density, dislocation geometry and peculiarities of formation of different types of substructures in local zones of welded metals. At that, as an object for investigation the templates of steel plate were used. They were cut out from a central part of the contact zone, where the maximum area of surface geometry crushing was registered. A reference specimen was a plate from steel 20 in as-received state. In pressure welding of dissimilar metals, having different deformation resistance, the process of joining is limited by activation of the contact surface of harder metal [4]. Therefore, the peculiarities of dislocation structure change in the sub-surface layers of deformed metal after indicated above technological effect were examined in the contact zone from the side of indicated type of metal, namely, steel 20.

Experiment results. Examinations of a fine structure of sub-surface layers of the plate from steel 20 in as-received state showed that the analyzed structure is characterized by general minimum volumetric dislocation density making from $\rho \sim 10^{8}$ to $\sim 2 \cdot 10^{9} \mathrm{~cm}^{-2}$, comparably uniform structure of intergranular boundaries, stable dimensions of around $0.65-1 \mu \mathrm{m}$ (Figure 1, $a$ ) of substructure elements (subgrains and cells) as well as clearly directed cementite plates without deformation signs (Figure $1, b$ ).

After treatment of the compressed plates by current pulses the structure of sub-surface layers of plates from steel 20 takes abundant signs of deformation, namely:

- sufficiently high dislocation density from $\rho \sim$ $\sim 10^{10}$ to $\sim 10^{11} \mathrm{~cm}^{-2}$ was registered along the examined surface. It is almost 2 times higher the dislocation density of metal surface in as-received state;

- structure of separate grains is significantly fragmented with formation of pronounced boundaries of fragments (in Figure 2, $a$ intragranular fragments of $\sim(1.2-1.5) \mu \mathrm{m}$ size are registered);

- crushing (breaking) of cementite plates takes place. Such an effect, as a rule, occurs after cold treatment of metal (Figure 2, b);

- structural details of the zones of geometry combs crushing are clearly developed. They represent itself a laminar pattern, including a system of shear (deformation) bands (Figure 2,c) forming as a result of upsetting of roughness peaks in deformation. Appearance of the shear bands (distortion of slip bands) of different width from 2 to $4 \mu \mathrm{m}$ is caused by the

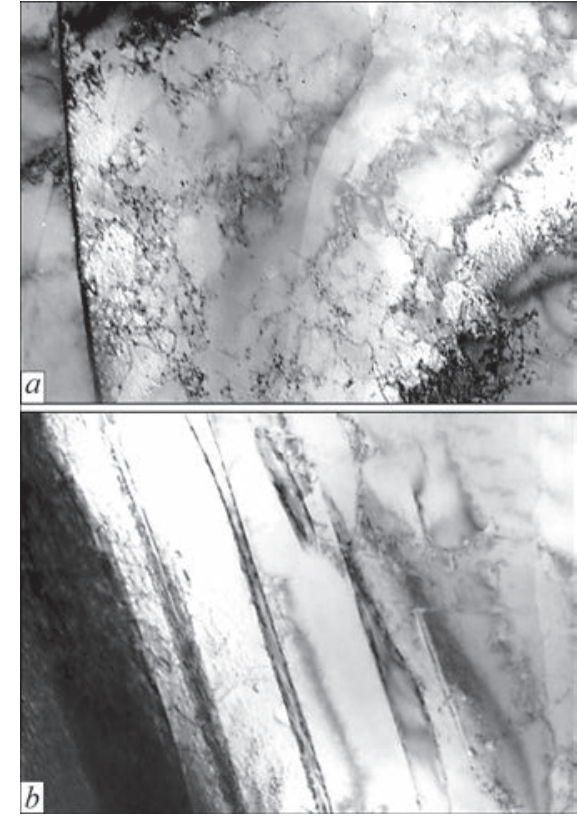

Figure 1. Dislocation structure of sub-surface layers of plates from steel 20 in as-received state: $a-$ stressless grain boundary and cell structure $(\times 20000) ; b-$ undeformed cementite plates $(\times 30000)$

peculiarities of dislocation configuration, i.e. their accumulation in the boundary slip bands. Shear band length of $>>8 \mu \mathrm{m}$ was registered;

- fragmentation of structure, related with actively passing (in parallel with plastic deformation processes) relaxation processes are observed inside the separate shear bands. In Figure 2, $d$ the relaxation is developed as formation of blocks (almost perfect areas with discrete mutual misorientation) of $0.6-$ $1.2 \mu \mathrm{m}$ size in the shear band from 3.3 to $3.5 \mu \mathrm{m}$. Figure 2, $e$ shows structure fragmentation in the shear band of $h=1-3.7 \mu \mathrm{m}$ size, accompanied by formation of ball-cellular structure with dislocation density $\rho \approx 8.6 \cdot 10^{9} \mathrm{~cm}^{-2}$.

It should be noted that in the structure of crushed roughness combs, in addition to shear band system, there are also cavities of different depth. They are characterized by lower dislocation density, corresponding on value to dislocation density in undeformed metal. These zones are the areas, where physical contact has not been yet formed, as a result of what the corresponding areas of the joint contain the pores, further healing of which is possible in a diffusion way by means of subsequent heating. Figure 2, $f$ shows the structure of shear bands in roughness combs crushing, where structure of the roughness cavity (light area - potential pores) is subgrains of $\sim 0.75 \mu \mathrm{m}$ size and cells from 0.13 to $0.2 \mu \mathrm{m}$ size with minimum density dislocation. Sufficiently high dislocation density, approximately $10^{11} \mathrm{~cm}^{-2}$, is registered in the zone of roughness comb deformation (dark area — zone of deformation).

Analysis of obtained research results of the fine structure of the sub-surface layers of steel plate after treatment of preliminary compressed plates by current 

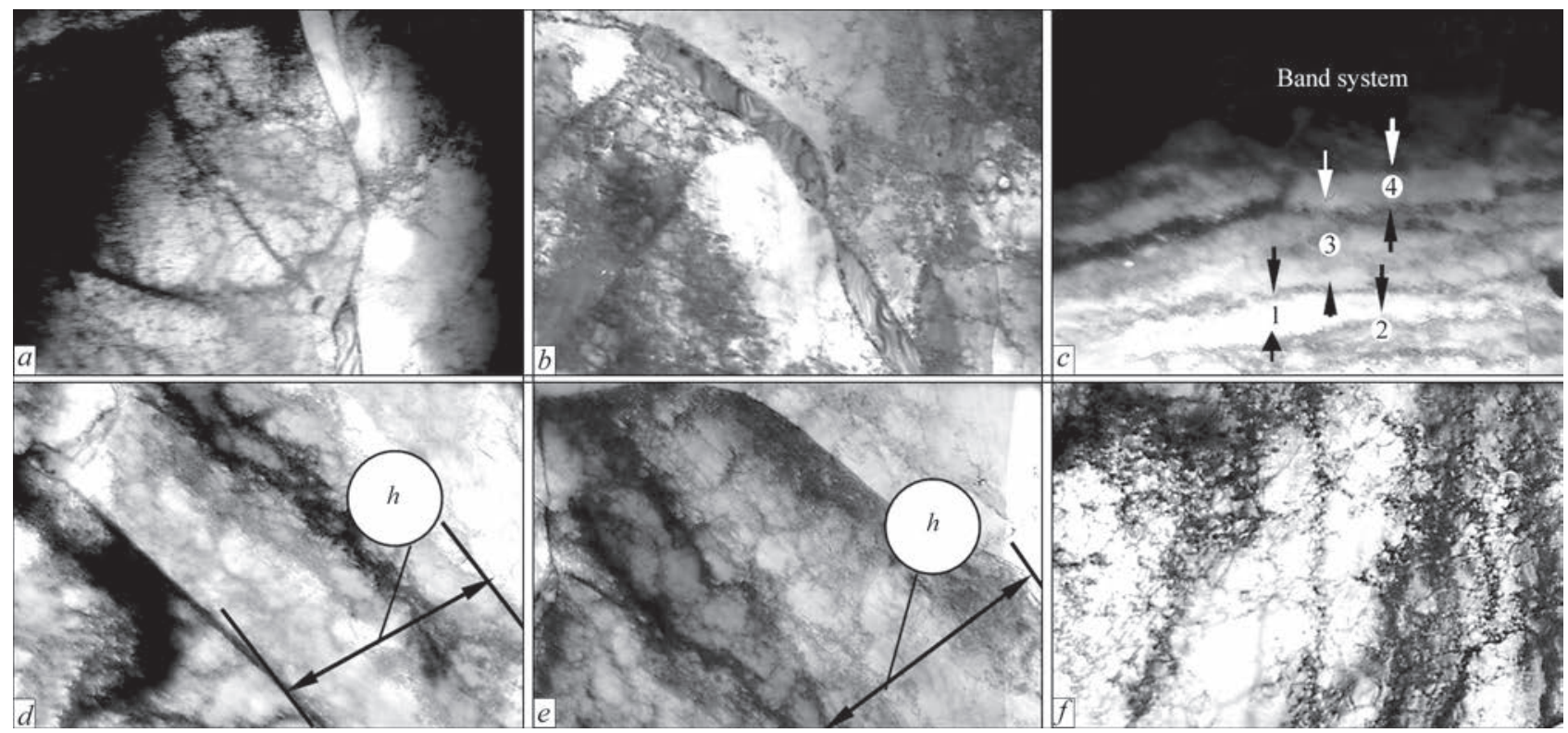

Figure 2. Dislocation structure of sub-surface layers of steel 20 plates after engineering effect: $a$ - grain fragmentation $(\times 15000)$; $b$ - broken cementite plate $(\times 15000) ; c$ - system of shear band $1-4(\times 10000)$; $d$ - formation of blocks in shear band $(\times 10000)$; $e-$ fragmentation of structure with formation of ball-cellular structure in shear band; $f$ - structure of shear layers in crushing of roughness comb $(\times 20000)$

pulses indicate that the separate microareas (roughness combs) as a results of technological influence become the zones with high level of deformation, having typical dislocation transformations of the following types:

- more than order increase of values of dislocation density in this area, that indicates significant rise of level of internal stresses in deformation local zone;

- nonuniformity of distribution of dislocation density in the zone of localizing of steel 20 surface deformation;

- formation of shear (deformation) bands as a result of upsetting of roughness combs in the process of deformation of steel surface layers caused by buildup of dislocation accumulations in the adjacent slip planes;

- significant structure fragmentation inside the deformation bands, accompanied by formation of ball-cellular structures, indicate a rapid activation of dislocation interaction and active transformation of the fine structure, that, as a result, promotes formation of ends of dislocation jogs so called active centers [4] on steel deformed surface, resulting in activation of the contact surface.

Thus, there are two simultaneous process taking place in areas of the deformed steel surface, namely formation of the physical contact and formation of the active centers, i.e. joining zones in the layers of surface deformation, that promotes for formation of interatomic bonding. Together with mentioned above, there are also the areas (roughness cavities - pores), at which formation of physical contact is not observed.

\section{Conclusions}

1. Different stages of the process of welded joint formation take place on the contact interaction surface, having macroscopic size. It is caused by inhomogeneity of real surfaces of solid bodies even at high class of their treatment. Therefore, division of the welding process on separate stages is only true for microscopic areas of the contact surface.

2. The results of examination of the fine structure of steel surface indicate that treatment with the high-density pulses results in significant dislocation transformations, which can significantly effect the development of the third stage of solid-state welding process, i.e. stage of volumetric interaction.

1. Middeldorf, K., von Hofe, D. (2008) Trends in joining technology. The Paton Welding J., 11, 33-39.

2. Reisgen, U., Stein, L., Steiners, M. (2010) Stahl-Aluminium-Mischverbindungen: Schweissen oder Loeten? Die Kombination zweier etablierter Fuegetechnologien macht Unmoegliches moeglich. Schweissen und Schneiden, 62(5), 278-284.

3. Karakozov, E.S. (1976) Joining of metals in solid phase. Moscow: Metallurgiya.

4. Karakozov, E.S. (1986) Pressure welding of metals. Moscow: Mashinostroenie.

5. Troitsky, O.A., Baranov, Yu.V., Avraamov, Yu.S. et al. (2004) Physical principles and technology of treatment of modern materials. Vol.1: Theory, technology, structure and properties. Moscow; Izhevsk: IKI.

6. Onatskaya, N.A., Demidenko, L.Yu. (2010) Influence of circuit processing by current pulses on formation of physical contact in pressure welding. Elektronn. Obrab. Materialov, 3, 19-21.

7. Vovchenko, A.I., Demidenko, L.Yu., Onatskaya, N.A. (2011) Intensification of plastic deformation of metal surfaces under action of current pulses in pressure welding. Naukovi Notatky, 32, 63-68.

Received 23.12.2015 